\title{
Understanding the Relationship Between the Retail Food Environment Index and Early Childhood Obesity Among WIC Participants in Los Angeles County Using GeoDa
}

\author{
Maria Koleilat ${ }^{1}$, Shannon E. Whaley ${ }^{1}$, Abdelmonem A. Afifi ${ }^{2}$, Leobardo Estrada ${ }^{3}$, \\ Gail G. Harrison 4 \\ ${ }^{1}$ Dept of Research and Evaluation, PHFE WIC Program, Irvindale, CA \\ ${ }^{2}$ Dept of Biostatistics, UCLA School of Public Health, Los Angeles, CA \\ ${ }^{3}$ Dept of Urban Planning, UCLA School of Public Affairs, Los Angeles, CA \\ ${ }^{4}$ Dept of Community Health Sciences, UCLA School of Public Health, Los Angeles, CA
}

\section{Abstract}

The aim of this study was to examine the association between the local food environment and obesity proportions among 3- to 4-year-old children who were participants in the WIC program in Los Angeles County using spatial analyses techniques. ArcGIS, spatial analysis software, was used to compute the retail food environment index (RFEI) per ZIP code. GeoDa, spatial statistics software was employed to check for spatial autocorrelation and to control for permeability of the boundaries. Linear regression and ANOVA were used to examine the impact of the food environment on childhood obesity. Fast-food restaurants represented $30 \%$ and convenience stores represented $40 \%$ of the sum of food outlets in areas where WIC participants reside. Although there was no statistically significant association between RFEI and 3- to 4-year-old obesity proportions among WIC children, analysis of variance (ANOVA) tests demonstrated statistically significant positive associations between obesity and the number of convenience stores and the number of supermarkets. Our findings suggest that RFEI, as currently constructed, may not be the optimal way to capture the food environment. This study suggests that convenience stores and supermarkets are a likely source of excess calories for children in low-income households. Given the ubiquity of convenience stores in low-income neighborhoods, interventions to improve availability of healthy food in these stores should be part of the many approaches to addressing childhood obesity. This study adds to the literature by examining the validity of the RFEI and by demonstrating the need and illustrating the use of spatial analyses, using GeoDA, in the environment/obesity studies.

Key words: spatial analysis; GeoDa; retail food environment index; convenience stores; fastfood restaurants; supermarkets; produce vendors; childhood obesity; WIC 


\section{Introduction}

High rates of obesity in early childhood are a major public health problem in the United States. ${ }^{1}$ The high prevalence of obesity in early childhood is of concern because of its associated complications and its link with adult obesity. ${ }^{2}$ Obese children are already experiencing predominately adult illnesses such as hypertension, hyperlipidemia, abnormal glucose tolerance, ${ }^{3}$ and type 2 diabetes. ${ }^{4}$ Children from minority communities, and particularly Latino children, are disproportionately affected by the epidemic of obesity. ${ }^{5}$ Previous studies have hypothesized that the communities in which low-income and minority families reside may contribute to the increased risk of obesity. ${ }^{6}$ This study aims to examine the impact of food environments, including fast food outlets, convenience stores, grocery stores and farmer's markets, on the prevalence of obesity among 3- to 4-year old participants of the Special Supplemental Nutrition Program for Women, Infants and Children (WIC).

The social ecological model for obesity prevention provides the context for this work, specifically the idea that health is a function of the built environment in which one lives. ${ }^{7,8}$ Understanding the complex interrelationships between individual factors, social environmental factors and the built environment can help define obesity prevention strategies. The media and the scientific literature have frequently blamed fast-food restaurants for higher caloric intake, lower vegetable consumption, rising obesity rates and health disparities in the US. ${ }^{9,10}$ Recently, the role of small convenience stores/corner stores has been highlighted. ${ }^{11-13} \mathrm{~A}$ recent study showed that calories from snack foods were a likely culprit for higher obesity rates in South Los Angeles. ${ }^{12}$ South Los Angeles had a dramatically higher concentration, compared to other sections of Los Angeles, of the type of small convenience stores that sell high calorie snacks. In another study examining the shopping patterns of schoolchildren in urban Philadelphia, Borradaile and colleagues found that half of the 800 students in their sample reported shopping at a corner store at least once a day, five times a week. ${ }^{11}$ Almost one third visited a store both before and after school; students spent about $\$ 1$ and purchased 356 calories of snack foods including chips, candy, gum and sugary beverages during each visit.

Conversely, a study exploring the role of supermarkets on obesity and its related chronic diseases has documented that the presence of supermarkets is related to lower rates of obesity. ${ }^{14}$ Access to supermarkets has been associated with more frequent fruit and vegetable consumption. ${ }^{15}$ Fullsize supermarkets were found to be less prevalent in racially mixed ${ }^{16-20}$ and low-income ${ }^{17,18-20}$ neighborhoods compared to higher-income and white neighborhoods. There has been speculation that this unequal distribution of healthy and unhealthy retail food outlets among communities is a likely contributor to the disparities in the risk of obesity. ${ }^{20,21}$

The current research explores the association between the proportions of childhood obesity among 3- to 4-year old WIC participants and the relative availability/distribution of various types of food outlets. We examine the distribution of fast-food restaurants, convenience stores, supermarkets, and produce vendors in areas where WIC participants reside, hypothesizing that more fast-food restaurants and convenience stores and fewer supermarkets and farmers' markets in close proximity to households are associated with higher obesity prevalence among 3- to 4year-old children in those households.

This study adds to the literature of the retail food environment and obesity by examining the very young 3- to 4-year-old WIC children in Los Angeles County who are predominately Latino, a 
group so far ignored in studies of the retail food environment and obesity. In Los Angeles County, the majority of children under five participating in WIC are Latino and nearly $40 \%$ have BMI levels greater than the $85^{\text {th }}$ percentile. ${ }^{22}$ Given the broad reach of the WIC Program in Los Angeles County to reach over $67 \%$ of all births in the county, ${ }^{23}$ linkages of WIC administrative data with retail food environment data have great potential to illustrate the role of community level factors on early childhood obesity. This study adds significantly to the literature by evaluating the validity of the RFEI, a widely used measure that has not been validated before. In addition, this study illustrates how to use spatial analyses to account for spatial correlation and permeability of geographic boundaries, two analytical issues so far ignored in the food environment/obesity studies.

\section{Methods}

\section{Data Sources}

WIC Data: Extensive information about WIC families is collected regularly in the California Integrated Statewide Information System (ISIS), including socio-demographic and health information. While ISIS has historically enabled the analysis of WIC administrative data at either the State level or local WIC agency level, it was not electronically aggregated for Los Angeles County, where seven local agency WIC Programs provide services. Funded by First 5 Los Angeles (F5LA), the Data Mining research partnership addressed the critical gap in information about low-income families in Los Angeles County. This partnership created an electronic system that supported the aggregation of WIC administrative data (ISIS) across the County, with an annual data download in March of each year. The 2008 WIC data included information on 538,555 WIC participants in Los Angeles County including women, infants and children. ZIP code level data were drawn from this dataset for this analysis.

Obesity Status of 3- to 4-Year-Old Children: The most recent weight and height measurements for each child downloaded in March 2008 were analyzed. Children ages 2-5 are considered obese if their Body Mass Index (BMI) is greater than or equal to the 95th percentile with regard to the standard reference population. ${ }^{24}$ As part of the WIC eligibility requirements, children must be weighed and measured every 6 months at a WIC site. All heights and weights are captured in ISIS. The child's height and weight measurements are taken as part of the WIC standard protocol. This protocol involves removing shoes and heavy outwear and measuring height using a stadiometer (model PE-WM-60-76) and weight with a scale (Health-O-Meter 402LB) that is calibrated every 6 months. Recent work by Crespi et al (In press: personal communication) ${ }^{25}$ has validated the use of height/weight measurements taken by PHFE WIC staff.

Demographic Measures: Income, race/ethnicity and education are potential covariates of any association between residential environments and obesity. Income was represented by proportions of WIC participants per ZIP code with income less than $100 \%$ of federal poverty level vs. proportions of WIC participants with incomes at or above $100 \%$ of poverty level. Race was represented by proportions of Latino WIC participants per ZIP code vs. non-Latino WIC participants. Education was represented by proportions of WIC participants per ZIP code with less than 12 years of education vs. proportions of WIC participants with 12 years of education or more. 
Food Retailer Data: The InfoUSA Business File from ESRI (Redlands, CA) was utilized to assess the retail food environment (Spring 2009). The database included 80,047 observations. From this dataset, we selected all fast-food restaurants; convenience stores; supermarkets and other grocery stores; and produces vendors according to the North American Industry Classification System (NAICS) code for restaurants. The NAICS is an industry classification system used to classify economic units that have similar processes in the same industry and specific codes used in this analysis are listed below.

Fast-Food Restaurants: As in a study published by the California Center for Public Health Advocacy (CCPHA), ${ }^{26}$ fast-food restaurants were defined following the National Restaurant Association's distinction between "table service" and "quick service (fast-food)" restaurants. In addition to counter service, fast-food restaurants are characterized by meal service (vs. snacks, dessert, and coffee) and low price (less than $\$ 7 /$ meal). We did not limit the inclusion of fast-food outlets to the ones with five or more locations with the same names. Businesses with the following NAICS codes for restaurants were included: 72211002, 72211011, 72211012, 72211013, 72211016, 72211020, 72221101, 72221103, 72221104, and 72221105.

Convenience Stores. Businesses with NAICS code 44512001, such as 7-Elevens and other chains that do not sell gasoline or other fuel, were included as convenience stores. We also included supermarkets and grocery stores that had two or fewer employees (NAICS codes: 44511001, 44511002, 44511003, 44511004, and 44511005).

Supermarkets and Other Grocery Stores: Establishments with more than two employees engaged in retailing canned and frozen food, fresh fruits and vegetables, fresh and prepared meats, fish, and poultry were included as supermarkets and grocery stores (NAICS codes included 44511001, 44511002, 44511003, 44511004, and 44511005).

Produce Vendors: Produce vendors included produce stores (NAICS codes 44523001 and 44523003), and 2009 farmers'markets. ${ }^{27}$ Information regarding the actual physical locations of farmers' markets was verified using Google maps.

\section{Statistical Analysis}

SAS version 9.2 (2008, SAS Institute, Inc, Cary, NC) was used to describe the sample. The number of fast-food restaurants, convenience stores, supermarkets and other grocery stores and produce vendors was determined for each ZIP code in Los Angeles County. ArcGIS version 9.3.1 (2009, ESRI, Redlands, CA) was used to compute a Retail Food Environment Index (RFEI) for every ZIP code in Los Angeles County. RFEI measures the relative availability of different types of food retailers in ZIP codes where WIC participants reside ${ }^{26,28}$ It is defined as follows:

RFEI $=\ldots$ fast-food restaurants + convenience stores

Supermarkets + other grocery stores + produce vendors 
The index was determined for each ZIP code in Los Angeles County where WIC participants resided. A high RFEI indicated that a ZIP code had a large number of fast-food restaurants and convenience stores compared to supermarkets, other grocery stores and produce vendors. For example, a ZIP code with an RFEI of 2.0 had twice as many fast-food restaurants and convenience stores as supermarkets, other grocery stores and produce vendors. ${ }^{26}$ Linear regression and ANOVA were used to examine the impact of the food environment on childhood obesity. First, three linear regressions were conducted to examine the association between RFEI and obesity proportions. Model 1 included only RFEI as a predictor, Model 2 included the spatially lagged RFEI as a predictor and Model 3 included RFEI, income, race and education as predictors. ZIP codes were then divided into quartiles based on the proportions of 3- to 4-year old children who were obese (lowest, $2^{\text {nd }}, 3^{\text {rd }}$ and highest quartile). ANOVA was used to compare the mean number of each type of food outlet by level of obesity in that ZIP code.

\section{Spatial Data Analysis}

\section{Why Spatial Data Analysis?}

Most studies investigating the influence of the built environment on obesity use nonspatial methods such as multilevel modeling ${ }^{29}$ or general linear models, ${ }^{30}$ ignoring two analytical issues that can bias results in studies of geographic places: spatial autocorrelation and permeability of the boundaries. ${ }^{31}$ Legacy GeoDa 0.95i (2003, Arizona State University), a spatial statistics software, was used to help account for these analytical issues and better model the problem of childhood obesity among WIC participants.

\section{Descriptive Spatial Techniques}

Exploratory spatial data analysis (ESDA) was used to examine whether data collected from different areas exhibited complete randomness or spatial dependence, ${ }^{32}$ in other words to identify spatial autocorrelation and spatial outliers. ${ }^{33,34}$ As part of ESDA, the Moran scatter plot was constructed and the Moran's I coefficient was computed. The latter allows quantification of the extent to which spatial association is present. In general, a significant Moran coefficient indicates that the rates of obesity across neighborhood areas are correlated so spatial statistics may be necessary.

\section{Weight Matrices}

It is necessary to identify the "adjacencies" matrix or connection matrix, meaning identify which units are neighbors to one another prior to computing the Moran's I coefficient. There are two types of weight matrices; the contiguity-based spatial weight matrix and the distance-based spatial weight matrix. ${ }^{31,33}$ For this study, based on the hypothesis that people might shop or have a meal at food outlets in neighboring ZIP codes, the contiguity-based matrix (Queen's matrix) was selected. This identifies neighboring areas based on shared borders and vertices.

\section{Spatially Lagged RFEI}

The same Queen's weight matrix was employed to compute the spatially lagged RFEI. The spatially lagged RFEI is the sum of spatial weights multiplied by values for RFEIs at neighboring locations. Including the spatially lagged RFEI as an independent variable in the 
Understanding the Relationship Between the Retail Food Environment Index and Early Childhood Obesity Among WIC Participants in Los Angeles County Using GeoDa

regression model examines whether a relationship exists between the type and distribution of food outlets in neighboring areas and the outcome measured within each target area.

\section{Results}

\section{Descriptive Summary Statistics}

Sample characteristics are shown in Table I. The study area comprised 266 ZIP codes in Los Angeles County. Almost $20 \%$ of the children were obese. More than $68 \%$ of the participants were Latino and almost $14 \%$ were White. The majority of WIC participants in this sample, almost $63 \%$, resided in households with incomes below $100 \%$ of the US federal poverty level and almost $40 \%$ of the participants resided in households where the highest level of education achieved was less than 12 years.

A total of 6,436 retail food outlets were identified in Los Angeles County in 2009, 40\% of which were convenience stores, $30 \%$ were fast-food restaurants, $24 \%$ were supermarkets, and $6 \%$ were produce vendors. The average RFEI for areas in Los Angeles County where WIC participants resided was 2.68, meaning that neighborhoods where WIC participants lived had more than twice as many fast-food restaurants and convenience stores as they did grocery stores and produce vendors. More than $85 \%$ of WIC participants resided in areas with an RFEI ranging between 1 and 5.

\section{Exploratory Spatial Data Analysis (ESDA)}

\section{Global Spatial Pattern: Moran's I}

The global Moran's I test statistic was used to quantify the degree to which data were clustered or uniformly distributed to check whether spatial autocorrelation existed. The results of the Moran's I scatter plot (Moran's I $=0.0475$ and $p=0.072$ ) did not suggest a strong spatial autocorrelation. Therefore, there was no need to run a spatial regression model, an ordinary least squares regression was appropriate.

\section{Regression Analyses and ANOVA}

The results of the simple linear regression models 1 and 2 showed no significant differences in the proportion of obese 3- to 4-year-old WIC children by RFEI $(P=0.69)$ and no statistically significant association between the proportion of 3- to 4-year-old obese WIC children and the spatially lagged RFEI $(P=0.95)$. Results of the Model 3 multiple regression analysis showed that when the proportion of Latino WIC participants increased by $1 \%$, the proportion of obese children increased by $0.14 \%$, holding all other variables constant $(P=0.04)$ (Table II). No other predictor variables were significantly related to childhood obesity (Table II).

Given the nonsignificant statistical association between RFEI and proportions of obese 3- to 4year-old WIC children, we examined the association between the number of stores for each type of food outlets and proportions of obese 3- to 4-year-old WIC children. ANOVA showed that while the number of fast-food restaurants, produce stores and farmers' markets did not vary much across quartiles of obesity for 3- and 4-year-old children, the number of convenience stores and supermarkets increased significantly across quartiles of obesity for 3 - to 4-year-old children 
Understanding the Relationship Between the Retail Food Environment Index and Early Childhood Obesity Among WIC Participants in Los Angeles County Using GeoDa

(Table 3). Rates of childhood obesity were highest in communities with more convenience stores and in communities with more supermarkets.

Table 1. Summary Statistics of WIC Variables on Average across ZIP Codes, Los Angeles County, 2008

\begin{tabular}{|l|l|}
\hline Variable & "Mean" or "Percent" \\
\hline BMI $\geq 95$ th percentile & $19.6 \%$ \\
\hline Race & \\
\hline Asian & $8.4 \%$ \\
\hline Black & $8.2 \%$ \\
\hline Latino & $67.9 \%$ \\
\hline Native American & $0.5 \%$ \\
\hline Pacific Islander & $0.4 \%$ \\
\hline Other & $0.6 \%$ \\
\hline White & $13.8 \%$ \\
\hline Poverty Level & \\
\hline Below 100\% Federal Poverty Level & $62.5 \%$ \\
\hline $100-133 \%$ Federal Poverty Level & $19.3 \%$ \\
\hline $133-185 \%$ Federal Poverty Level & $16.8 \%$ \\
\hline Above $185 \%$ Federal Poverty Level & $1.4 \%$ \\
\hline Highest Level of Education Completed in the Household & \\
\hline $0-4$ years & $3.1 \%$ \\
\hline $5-8$ years & $12.4 \%$ \\
\hline $9-11$ years & $24.1 \%$ \\
\hline 12 years & $38.6 \%$ \\
\hline $13-15$ years & $15.2 \%$ \\
\hline 16 years and up & $6.7 \%$ \\
\hline WIC Population per ZIP code (mean \pm sd) & $\sim 2010 \pm 2461$ \\
\hline Number of ZIP codes & 266 \\
\hline
\end{tabular}

Table 2. Multivariate Regression Results

\begin{tabular}{|l|l|l|l|}
\hline Regressor Variable & Coefficient & SE & P value \\
\hline RFEI & 0.00 & 0.00 & 0.679 \\
\hline $\begin{array}{l}\text { Proportion of WIC children residing in households with incomes below 100\% } \\
\text { of the US Federal Poverty Level vs. those with incomes above this level }\end{array}$ & 0.09 & 0.06 & 0.145 \\
\hline $\begin{array}{l}\text { Proportions of Hispanics WIC participants compared to proportions of other } \\
\text { races }\end{array}$ & 0.15 & 0.04 & $\mathbf{0 . 0 4 5}$ \\
\hline
\end{tabular}


Understanding the Relationship Between the Retail Food Environment Index and Early Childhood Obesity Among WIC Participants in Los Angeles County Using GeoDa

Proportions of WIC households where the highest level of education completed is less than 12 years compared to those with 12 years or more

\begin{tabular}{|l|l|l|}
0.04 & 0.05 & 0.510 \\
\hline
\end{tabular}

Table 3. Summary Statistics of Food Store Outlets per Quartiles of Obesity among 3- to 4-YearOld Children, Los Angeles County, 2008 (full sample of ZIP codes N =266)

\begin{tabular}{|l|l|l|l|l|l|}
\hline & \multicolumn{4}{|l|}{ Number of Outlets per ZIP code (mean (sd)) } \\
\hline Quartiles of Obesity & $\begin{array}{l}\text { Fast-food } \\
\text { restaurants }\end{array}$ & $\begin{array}{l}\text { Convenience } \\
\text { stores* }\end{array}$ & Supermarkets* & $\begin{array}{l}\text { Produce } \\
\text { stores }\end{array}$ & $\begin{array}{l}\text { Farmers } \\
\text { markets }\end{array}$ \\
\hline $\begin{array}{l}\text { Lowest quartile: } 0.00- \\
\text { 16.67\% }(N=65)\end{array}$ & $6.8(5.1)$ & $\mathbf{4 . 1}(\mathbf{5 . 2})$ & $\mathbf{4 . 0}(\mathbf{3 . 2})$ & $0.5(1.1)$ & $0.5(0.7)$ \\
\hline $\begin{array}{l}\text { 2nd quartile: } 16.68- \\
\text { 20.16\% }(N=68)\end{array}$ & $7.0(4.2)$ & $\mathbf{7 . 1 ( 6 . 4 )}$ & $\mathbf{5 . 2 ( 3 . 3 )}$ & $0.5(0.7)$ & $0.4(0.6)$ \\
\hline $\begin{array}{l}\text { 3rd quartile: } 20.17 \%- \\
\text { 22.74\% }(N=67)\end{array}$ & $8.0(4.4)$ & $\mathbf{1 3 . 8 ( 1 0 . 3 )}$ & $\mathbf{7 . 5 ( 4 . 0 )}$ & $1.1(2.0)$ & $0.4(0.7)$ \\
\hline $\begin{array}{l}\text { Highest quartile: } 22.75 \%- \\
52.63 \%(N=66)\end{array}$ & $6.4(3.8)$ & $\mathbf{1 2 . 8 ( 1 4 . 1 )}$ & $\mathbf{6 . 8 ( 4 . 7 )}$ & $1.8(10.4)$ & $0.4(0.6)$ \\
\hline
\end{tabular}

$* P<0.0001$, as indicated by analysis of variance

\section{Discussion}

We found no statistically significant association between the proportion of 3- to 4-year-old obese WIC children and the relative availability of different types of food retailers as represented by RFEI. Also, the spatially lagged RFEI did not turn out to be statistically significant, implying a lack of a spatial lag effect for our main independent variable, RFEI. These findings are consistent with the few studies that have looked at the environmental determinants of childhood obesity, ${ }^{35}$ suggesting that the built-environment-childhood obesity relationship is still poorly understood. Our findings also suggest that the RFEI may obscure the effects of the different components of the index on childhood obesity. Supermarkets are in the denominator in the RFEI, and are thus considered protective. In fact, examination of availability of each type of food outlet individually showed that the number of convenience stores and the number of supermarkets increased significantly as obesity rates of 3- to 4-year old children went up, thus calling into question the protective effect of supermarkets. Until we know more about the effects of supermarkets on childhood obesity, results based on the RFEI should be interpreted with caution.

While in past years the tendency has been to focus on fast food outlets as contributing to the rising obesity epidemic, findings from this study suggest that the ubiquitous availability of convenience stores should not be overlooked. Descriptive statistics demonstrated that while fastfood restaurants represented $30 \%$ of the total number of food outlets in areas where WIC 
participants resided, convenience stores totaled $40 \%$, despite excluding convenience stores associated with gas stations from these analyses. Rates of childhood obesity were highest in communities with more convenience stores and in communities with more supermarkets. These findings are not surprising given the limited availability and high price of fresh produce and widespread availability of high calorie foods in convenience stores. These small stores sell items such as soft-drinks, candy, ice-cream, and occasionally grocery items. Most of these stores are open 24 hours, making them a source of readily available inexpensive calorie-dense food. Findings are consistent with recent studies that have examined the link between convenience stores/corner stores and obesity. ${ }^{11-13,36}$ More qualitative research is necessary if we are to understand the obesogenic factors within these stores and the associations between food environment, food retail usage and food consumption patterns.

Findings regarding supermarkets and childhood obesity were not consistent with the majority of literature as supermarket availability was associated with higher obesity rates among 3- to 4year-old children. Studies have found that full-size supermarkets are less prevalent in predominately racially mixed and low-income neighborhoods compared to higher income and white neighborhoods. ${ }^{16-20}$ However, living near a supermarket has been found to be associated with lower prevalence of obesity and overweight, presumably due to greater availability of healthy food options. ${ }^{14}$ These data suggest that the impact of supermarkets on childhood overweight merits more study. It is likely that supermarkets carry both healthy and unhealthy food items and the decision regarding which items to buy depends on factors other than availability alone, such as price, preference, and location in the store. In fact, some studies have found that supermarkets in census tracts with predominately black residents generally carry fewer healthy food options than supermarkets in other neighborhoods. ${ }^{37}$ Another study found that the ratio of energy-dense snack foods to produce in full-size supermarkets is greater than that of corner stores and medium sized grocers and only exceeded by convenience stores. ${ }^{38}$ As this was not a qualitative study, we cannot describe the foods carried by supermarkets in lowincome community. Moreover, the significant correlation $(P<.0001)$ between the number of supermarkets and number of convenience stores could very well be another potential explanation for the unexpected association between child obesity rates and the number of supermarkets. Future research is needed to better understand the important role of supermarkets and access to healthy and unhealthy foods.

\section{Conclusion}

In conclusion, the current study suggests that convenience stores and supermarkets are associated with early childhood overweight and may be a source of excess calories. Healthy food availability and accessibility is a matter of equity and social justice and healthy food must be made available and affordable in every community. More studies are needed if we are to understand how to make healthy food more available and accessible in low-income communities. Improvements to this line of investigation should be made and include evaluating different environmental factors and using spatial analyses techniques to control for spatial autocorrelation and permeability of the boundaries. Meanwhile, given the ubiquity of convenience stores, these food outlets should be regarded as a potential asset for improving diet quality of residents in lowincome neighborhoods. Interventions providing incentives to store owners to improve 
availability of healthy foods in their stores should be part of the many approaches to addressing childhood obesity.

\title{
Study Limitations
}

Our study has limitations that need to be acknowledged. First, due to confidentiality reasons, we were not able to obtain the participants' individual-level data and addresses; therefore this study incorporated only group level data. Lack of individual-level data meant that we were not able to compute the simultaneous effects of group-level variables and individual-level variables on the outcomes of interest; and lack of addresses meant that we were not able to investigate measures of distance. However, although the use of multilevel modeling is a great advancement, these models often fail to examine model fit from a spatial perspective and to recognize that there is additional information to be gained by using spatial statistics tools, such as examining models for spatial autocorrelation in the unexplained variance. That is why our results concerning the relationship between RFEI and early childhood obesity using spatial analyses techniques does make an original contribution to the literature in the area of obesity and the built environment.

Our second limitation concerns causality and generalization of our findings. Like the majority of studies in this field, this is a cross-sectional study and causality cannot be determined. Moreover, due to the racial and geographic distribution of this population, we cannot generalize our findings beyond our study population: predominantly 3- to 4-year-old WIC children in Los Angeles County. Insomuch as this is a group so far ignored in studies of the retail food environment and obesity, we feel this study fills an important gap in the literature. Finally, the use of InfoUSA data has been criticized for having many missing outlets. ${ }^{39}$ It is unlikely, however, that this bias would vary as a function of our childhood obesity rates and thus should not have influenced our findings. Despite these limitations, our study has unique strengths that include examination of the validity of the RFEI index that was previously used in public policy papers but never validated, use of spatial analyses to account for the analytical issues that arise from studying neighboring areas, and reliance on measured height and weight data, thus avoiding a potential significant misclassification bias that can arrive from self-reported heights and weights. $^{40}$

\section{Acknowledgements}

This work was supported by USDA/CSREES\#2005-35215-16075 and First 5 LA.

\section{Corresponding Author}

\author{
Maria Koleilat \\ Postdoctoral Research Analyst \\ Department of Research And Evaluation \\ PHFE-WIC Program \\ Irwindale, $\mathrm{CA}$ \\ Email: mariak@phfewic.org
}


Understanding the Relationship Between the Retail Food Environment Index and Early Childhood Obesity Among WIC Participants in Los Angeles County Using GeoDa

\section{References}

1. Ogden, C.L., Carroll, M.D., Curtin, L.R., Lamb, M.M., Flegal, K.M. (2012). Prevalence of high body mass index in US children and adolescents, 1999-2010. JAMA. Published Online January 17. 2. Singh S, Mulder C, Twisk JW, van Mechelen W, Chinapaw MJ. 2008. Tracking of childhood overweight into adulthood: a systematic review of the literature. Obes Rev. 9, 474-88. http:// dx.doi.org/10.1111/j.1467-789X.2008.00475.x

3. Freedman, D.S, Mei, Z., Srinivasan, S.R., Berenson, G.S., Dietz, W.H. (2007). Cardiovascular risk factors and excess adiposity among overweight children and adolescents: the Bogalusa Heart Study. J Pediatr, 150(1),12-17. e12.

4. Goran MI, Ball GDC, Cruz ML. 2003. Obesity and risk of type 2 diabetes and cardiovascular disease in children and adolescents. J Clin Endocrinol Metab. 88, 1417-27. http:// dx.doi.org/10.1210/jc.2002-021442

5. Kimbro RT, Brooks-Gunn J, McLanahan S. 2007. Racial and ethnic differentials in overweight and obesity among 3-year-old children. Am J Public Health. 97, 298-305. http://dx.doi.org/10.2105/ AJPH.2005.080812

6. Story M, Kaphingst KM, Robinson-O'Brien R, Glanz K. 2008. Creating healthy food and eating environments: policy and environmental approaches. Annu Rev Public Health. 29, 253-72. http:// dx.doi.org/10.1146/annurev.publhealth.29.020907.090926

7. Green L, Richard L, Potvin L. 1996. Ecological foundations of health promotion. Am J Health Promot. 10(4), 270-81. http://dx.doi.org/10.4278/0890-1171-10.4.270

8. Kok G, Gottlieb N, Commers M, Smerecnik C. 2008. The ecological approach in health promotion programs: a decade later. Am J Health Promot. 22(6), 437-42. http://dx.doi.org/10.4278/ ajhp.22.6.437

9. Taveras EM, Berkey CS, Rifas-Shiman SL, et al. 2005. Association of consumption of fried food away from home with body mass index and diet quality in older children and adolescents.

Pediatrics. 116, e518-24. http://dx.doi.org/10.1542/peds.2004-2732

10. Jeffery R, Baxter J, McGuire M, Linde J. 2006. Are fast food restaurants an environmental risk factor for obesity? Int J Behav Nutr Phys Act. 3, 2. http://dx.doi.org/10.1186/1479-5868-3-2

11. Borradaile K, Sherman S, Vander Veur S, et al. 2009. Snacking in children: the role of urban corner stores. Pediatrics. 124(5), 1293-98. http://dx.doi.org/10.1542/peds.2009-0964

12. Sturm R, Cohen DA. 2009. Zoning for health? The year-old ban on new fast-food restaurants in South LA. Health Aff. 28, w1088-97. http://dx.doi.org/10.1377/hlthaff.28.6.w1088

13. Lucan S, Karpyn A, Sherman S. 2010. Storing empty calories and chronic disease risk: snackfood products, nutritive content, and manufacturers in Philadelphia corner stores. J Urban Health. 87(3), 394-409. http://dx.doi.org/10.1007/s11524-010-9453-5

14. Morland K, Diez Roux AV, Wing S. 2006. Supermarkets, other food stores, and obesity: the atherosclerosis risk in communities study. Am J Prev Med. 30(4), 333-39. http://dx.doi.org/10.1016/ j.amepre.2005.11.003

15. Rose D, Richards R. 2004. Food store access and household fruit and vegetable use among participants in the US food stamp program. Public Health Nutr. 7, 1081-88. http:// dx.doi.org/10.1079/PHN2004648

16. Galvez MP, Morland K, Raines C, et al. 2007. Race and food store availability in an inner city neighbourhood. Public Health Nutr. 11(6), 624-31.

17. Moore LV, Diez Roux AV. 2006. Associations of neighborhood characteristics with location and type of food stores. Am J Public Health. 96(2), 325-31. http://dx.doi.org/10.2105/

AJPH.2004.058040

Online Journal of Public Health Informatics * ISSN 1947-2579 * http://ojphi.org * Vol.4, No. 1, 2012 
Understanding the Relationship Between the Retail Food Environment Index and Early Childhood Obesity Among WIC Participants in Los Angeles County Using GeoDa

18. Morland K, Filomena S. 2007. Disparities in the availability of fruits and vegetables between racially segregated urban neighborhoods. Public Health Nutr. 10(12), 1481-89. http:// dx.doi.org/10.1017/S1368980007000079

19. Morland K, Wing S, Diez Roux AV. 2002. The contextual effect of the local food environment on residents' diets: the atherosclerosis risk in communities study. Am J Public Health. 92(11), 1761-67. http://dx.doi.org/10.2105/AJPH.92.11.1761

20. Powell LM, Slater S, Mirtcheva D, Bao Y, Chaloupka FJ. 2007. Food store availability and neighborhood characteristics in the United States. Prev Med. 44, 189-95. http:// dx.doi.org/10.1016/j.ypmed.2006.08.008

21. Larson NI, Story MT, Nelson MC. 2009. Neighborhood environments: disparities in access to healthy foods in the US. Am J Prev Med. 36(1), 74-81. http://dx.doi.org/10.1016/ j.amepre.2008.09.025

22. Healthy City. Community data. (2009). Available at: http://www.healthycity.org/. Accessed January 20, 2012.

23. PHFE WIC. (2010). WIC data 2003-2009: A report on low-income families with young children in Los Angeles County. Available at: http://www.phfewic.org/Projects/Docs/ DataMining/Survey/WICDataReport2003-2009.pdf Accessed January 18, 2012.

24. Centers for Disease Control and Prevention. (2011). Childhood overweight and obesity. Available at: http://www.cdc.gov/obesity/childhood/. Accessed January 18, 2012.

25. Crespi K, Alfonse V, Whaley S, Wang M. Validity of child anthropometric measurements in the Special Supplemental Nutrition Program for Women, Infants and Children. Pediatr Res. (In press).

26. California Center for Public Health Advocacy. (2007). Searching for healthy food: the food landscape in California cities and counties. Available at: http://www.publichealthadvocacy.org/ searchingforhealthyfood.html. Accessed January 18, 2012.

27. County of Los Angeles. Agricultural Commissioner/Weights and Measures. Certified farmers' markets. It was available at: www.acwn.co.la.ca.us/scripts/CFM print.cfm. Accessed July 2009.

28. California Center for Public Health Advocacy. PolicyLink, and the UCLA Center for Health Policy Research. (2008). Designed for disease: The link between local food environments and obesity and diabetes. Available at: http://www.publichealthadvocacy.org/PDFs/RFEI\%20Policy \%20Brief finalweb.pdf Accessed January 18, 2012.

29. Ross NA, Tremblay S, Khan S, Crouse D, Tremblay M, et al. 2007. Body mass index in urban Canada: neighborhood and metropolitan area effects. Am J Public Health. 97, 500-08. http://dx.doi.org/10.2105/AJPH.2004.060954

30. Burdette HL, Whitaker RC. 2004. Neighborhood playgrounds, fast food restaurants, and crime: relationships to overweight in low-income preschool children. Prev Med. 38, 57-63. http://dx.doi.org/10.1016/j.ypmed.2003.09.029

31. Freisthler B, Lery B, Gruenewald PJ, Chow J. 2006. Methods and challenges of analyzing spatial data for social work problems: the case of examining child maltreatment geographically. Soc Work Res. 30, 198-210. http://dx.doi.org/10.1093/swr/30.4.198

32. Bailey TC, Gatrell AC. (1995). Interactive spatial data analysis. Addison Wesley Longman. 33. Anselin L. (2003). GeoDa ${ }^{\mathrm{TM}} 0.9$ user's guide. Urbana: Spatial Analysis Laboratory, Department of Agricultural and Consumer Economics, University of Illinois, UrbanaChampaign and Center for Spatially Integrated Social Science. 
34. Anselin L. (2005). Exploring spatial data with GeoDa: a workbook, revised edition. Center for Spatially Integrated Social Science, University of Illinois: Urbana-Champaign.

35. Papas MA, Alberg AJ, Ewing R, Helzlsouer KJ, Gary TL, et al. 2007. The built environment and obesity. Epidemiol Rev. 29, 129-43. http://dx.doi.org/10.1093/epirev/mxm009

36. Galvez MP, Hong L, Choi E, Liao L, Godbold J, et al. 2009. Childhood obesity and neighborhood food-store availability in an inner-city community. Acad Pediatr. 9(5), 339-43. http://dx.doi.org/10.1016/j.acap.2009.05.003

37. Baker E, Schootman M, Barnidge E, Kelly C. 2006. The role of race and poverty in access to foods that enable individuals to adhere to dietary guidelines. Prev Chronic Dis. 3(3), 1-11.

38. Farley TA, Rice J, Bodor JN, Cohen DA, Bluthenthal RN, et al. 2009. Measuring the food environment: shelf space of fruits, vegetables, and snack foods in stores. J Urban Health. 86(5), 672-82. http://dx.doi.org/10.1007/s11524-009-9390-3

39. Liese AD, Colabianchi N, Lamichhane AP, Barnes TL, Hibbert JD, et al. 2010. Validation of 3 food outlet databases: completeness and geospatial accuracy in rural and urban food environments. Am J Epidemiol. 172, 1-10. http://dx.doi.org/10.1093/aje/kwq292

40. Akinbami LJ, Ogden CL. 2009. Childhood overweight prevalence in the United States: the imr dx.do1.ı 